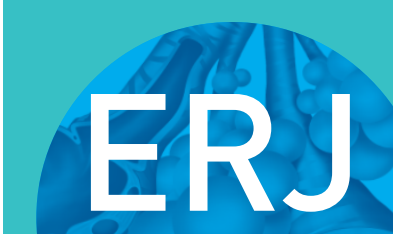

open research



\title{
Persistence of chronic cough in a community-based population
}

\author{
Anne M. Lätti (1) ${ }^{1,2}$, Juha Pekkanen $\mathbb{1}^{3,4}$ and Heikki O. Koskela (1) ${ }^{1,2}$
}

Affiliations: ${ }^{1}$ Unit for Medicine and Clinical Research, Pulmonary Division, Kuopio University Hospital, Kuopio, Finland. ${ }^{2}$ School of Medicine, Institute of Clinical Sciences, Faculty of Health Sciences, University of Eastern Finland, Kuopio, Finland. ${ }^{3}$ Dept of Public Health, University of Helsinki, Helsinki, Finland. ${ }^{4}$ Environmental Health Unit, National Institute for Health and Welfare, Kuopio, Finland.

Correspondence: Anne M. Lätti, Unit for Medicine and Clinical Research, Pulmonary Division, Kuopio University Hospital, Kuopio, PL 100, 70029 KYS, Finland. E-mail: anne.lattiakuh.fi

ABSTRACT Chronic cough causes significant impairment in the quality of life and is often immune to treatment. Previous studies about its persistence have focused on patients managed in special cough clinics. Little is known about the persistence of chronic cough in unselected populations. In this prospective follow-up study, we investigated factors that predict the persistence of cough at 12-month follow-up in a community-based study of subjects with chronic cough.

The first e-mail survey in 2017 included a questionnaire about current cough and its risk factors. The 264 subjects who reported chronic cough were sent a follow-up questionnaire 12 months later.

The response rate was $77.7 \%$ (205 subjects), of whom 165 subjects (80.5\%) still had cough in 2018 . In multivariate analysis, the following baseline factors predicted the persistence of cough at 12 months; gastro-oesophageal reflux disease (adjusted OR (aOR) 5.02 (95\% CI 1.10-22.83)), presence of a chemical trigger (aOR 2.88 (95\% CI (1.20-7.00)), duration of cough more than 1 year (aOR 2.80 (95\% CI 1.27-6.22)), frequent somatic symptoms (aOR 1.31 (95\% CI 1.07-1.59)), and low number of family members (aOR 0.71 (95\% CI 0.52-0.98)).

In conclusion, most patients with chronic cough still suffer from cough 1 year later. The presence of gastro-oesophageal reflux disease is the main predictor for the persistence of cough.

@ERSpublications

Most patients with chronic cough still suffer from cough 1 year later. The presence of gastrooesophageal reflux disease is the main predictor for the persistence of cough. http://bit.ly/ 2wMLPs1

Cite this article as: Lätti AM, Pekkanen J, Koskela HO. Persistence of chronic cough in a communitybased population. ERJ Open Res 2020; 6: 00229-2019 [https://doi.org/10.1183/23120541.00229-2019].

This article has supplementary material available from openres.ersjournals.com

Received: 4 Sept 2019 | Accepted after revision: 4 March 2020

Copyright $\odot$ ERS 2020. This article is open access and distributed under the terms of the Creative Commons Attribution Non-Commercial Licence 4.0. 


\section{Introduction}

Chronic cough is a troublesome disorder in many ways. Cough is the most common reason why people seek medical help [1, 2], it significantly decreases the quality of life [3] and individuals suffering from chronic cough feel debilitated [4]. Two previous studies reported that 50-60\% of patients with chronic cough still suffer from the disorder 5 to 7 years after the initial evaluation [5, 6]. However, the majority of the patients in these studies had been recruited from specialised cough clinics. As only the most severe and long-standing forms of cough are usually managed in specialised cough clinics, these studies are prone to bias towards over-pessimism in the prognosis of chronic cough. To the best to our knowledge, there are no studies that have examined the persistence of chronic cough in a community-based sample.

Of the studies investigating the issue, only one could define the predictors of cough persistence. That study reported that the possible determinants of cough persistence were chronic rhinitis or reflux disease and mild responsiveness to histamine and severe cough responsiveness to hypertonic saline [5]. However, it is not clear whether these predictors also apply in a population-based sample without the possibility to special investigations like histamine and saline challenges.

In order to improve our understanding of chronic cough, it would be important to obtain up-to-date information about the persistence and risk factors of chronic cough in a nonselected population. In this study, we examined the factors that predicted the presence of cough at 12 months in a community-based sample of subjects reporting chronic cough.

\section{Methods}

\section{Study design and population}

This was a prospective, observational follow-up study conducted in public service employees of two middle-sized towns in central Finland (Kuopio and Jyväskylä; altogether 13980 employees, mean 46.6 years of age, $79.2 \%$ of whom were females). An invitation to the study and the first questionnaire were sent via e-mail to the employees' e-mail addresses between March and April 2017. Answers were collected via an electronic reply form. One reminder was sent to the individuals who had not responded within 2 weeks. A total of 3695 subjects (26.4\%) responded, out of whom 419 (11.3\%) reported that they were suffering from chronic cough ( $>8$ weeks duration). The second questionnaire was sent via e-mail in April 2018 to all of those participants who reported suffering from chronic cough in the first inquiry in 2017 and who had provided permission for follow-up ( $n=264$, mean age 51.7 years (9.5), 83.0\% females) (figure 1). One reminder message was sent if a subject had not responded within 2 weeks. One phone contact was made if a subject had still not answered within 2 weeks after the reminder message.

The study was approved by the Ethics Committee of Kuopio University Hospital (289/2015). Permission to conduct the study was obtained from town officials. An informed, written consent was obtained from all participants.

\section{Questionnaires}

The first questionnaire sent in 2017 included questions about the subject's household, pets, moisture damage both in their workplace and at home, family incomes, occupation, physical activity, smoking history, alcohol consumption, current medications, recent (within 1 month) somatic symptoms, as well as all disorders diagnosed by a physician and general health-related questions. The questions were mainly adapted from two previous studies, the Health Behaviour and Health Among the Finnish Adult Population study [7] and the Finnish National FINRISK study [8]. Asthma-, rhinosinusitis- and reflux-related symptoms were enquired by questions currently employed in epidemiological studies [9-11]. Depressive symptoms were assessed by utilising the Patient Health Questionnaire-2 [12]. The first questionnaire also included 23 detailed cough-related questions to be filled in by subjects reporting current cough, such as questions about the frequency of coughing bouts and cough duration, as well as the Leicester Cough Questionnaire, which was used to measure cough-related quality of life [13]. An English version of the Finnish questionnaire sent in 2017 is included as a supplementary file.

The second questionnaire, sent in 2018, included questions about current cough, current smoking, current moisture damage both in the workplace and at home, current pets, and current medications. Both questionnaires were initially tested in a preliminary sample of 25 subjects and slightly revised before the final study.

\section{Definitions and outcomes based on questionnaires}

Chronic cough was defined as cough that had lasted more than 8 weeks [14]. Wheezing was defined as wheezing occurring but not attributable to flu during the previous 12 months [15]. Chronic rhinosinusitis was present if there was either nasal blockage or nasal discharge (anterior or posterior nasal drip) and either facial pain/pressure or reduction/loss of smell for more than 3 months [10]. Gastro-oesophageal 
Enrolments in the baseline survey in 2017 ( $n=13980)$

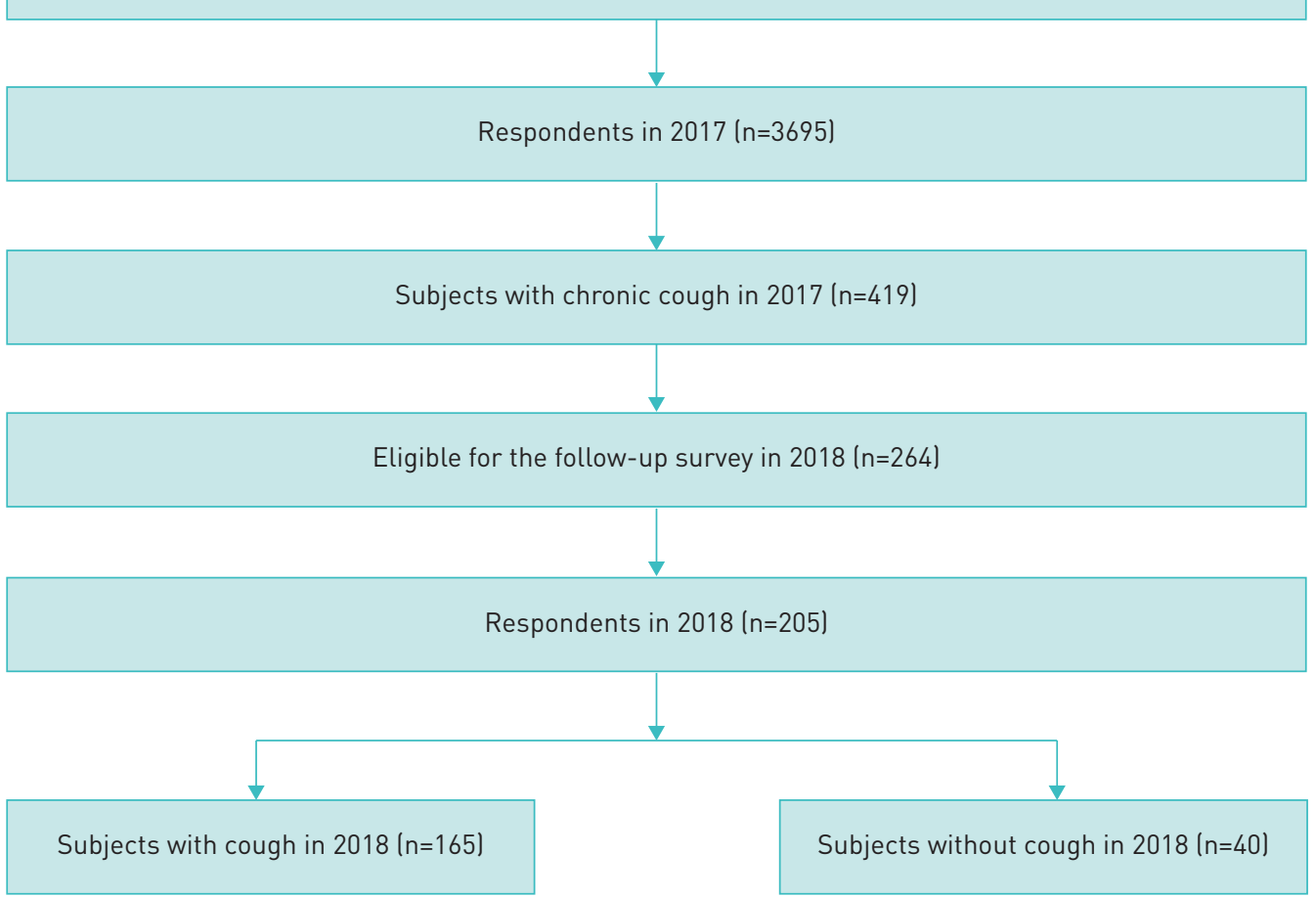

FIGURE 1 Flow chart of the study population.

reflux disease was present if the individual had experienced heartburn and/or regurgitation on at least 1 day per week during the last 3 months [11]. Depression was defined as a Patient Health Questionnaire-2 score of three or more [12]. The somatic symptom sum was calculated by summing all reported somatic symptoms except cough (including chest pain on exercise, arthralgia, back pain, toothache, leg oedema, varicose disorder, eczema, headache, sleeplessness, depression, other mental symptoms, constipation, diarrhoea or other gastro-intestinal symptoms, sciatica); it had a scale ranging from 0 to 14 . The presence of a chemical trigger for cough was defined as the presence of one or more of the following triggers that would either cause or worsen the cough: exhaust fumes, poor indoor air, cigarette smoke, strong odours or strong smells. Trigger sum was calculated by summing all of the cough triggers (including the chemical triggers defined above, upper respiratory tract infection, subfreezing air, physical exercise, pollens, speaking (adopted from Leicester Cough Questionnaire) or a free choice) giving a value from 0 to 12 . A family history of chronic cough was defined as the presence (now or in the past) of chronic (duration more than 8 weeks) cough in parents, sisters or brothers. The main outcome was the presence of cough in the past 2 weeks based on the questionnaire sent in 2018 .

\section{Statistical analysis}

Descriptive data are presented as means and 95\% confidence interval. Mann-Whitney U-test and chi-squared test were applied when appropriate. T-tests or other parametric tests were not used because most of the variables were not continuous or normally distributed. Table 1 shows the difference in the number of family members between the groups utilising the Mann-Whitney U-test. The following predictors were considered based on plausible biological associations with cough [14, 16-18]: age, sex, body mass index, years of education, professional status, unemployment or being laid off, family income, number of family members, pet ownership, ownership of dog and cat, exposure to moisture damage in the home or in the workplace, smoking history, alcohol consumption (total doses per week), family history of chronic cough, acetylsalicylic acid intolerance, the somatic symptom sum, the presence of a cough chemical trigger, the trigger sum, the use of cough remedies, cough bout frequency, cough duration more than 1 year (this cut-off value was defined by the Youlden index), Leicester Cough Questionnaire total score, wheezing, chronic rhinosinusitis, and gastro-oesophageal reflux disease. Confounders present in fewer than 10 respondents were not considered. The variables showing at least a suggestive $(\mathrm{p}<0.1)$ association with the outcome variables in the bivariate analyses were included in the multivariate analysis utilising binary logistic regression analysis with a backward-directed stepwise process. A p-value $<0.05$ was 
TABLE 1 Differences of baseline characteristics between subjects who presented cough and those who did not develop cough at the 12-month follow-up

\begin{tabular}{|c|c|c|c|}
\hline Characteristic at baseline & $\begin{array}{l}\text { Subjects with cough at follow-up } \\
\qquad(n=165)\end{array}$ & $\begin{array}{l}\text { Subjects without cough at follow-up } \\
\qquad(n=40)\end{array}$ & p-value \\
\hline Somatic symptom sum & $3.89(3.50-4.28)$ & $2.38(1.77-2.98)$ & $<0.001$ \\
\hline Trigger sum & $5.60(5.14-6.07)$ & $4.05(2.98-5.12)$ & 0.003 \\
\hline Presence of a chemical trigger & $84.8 \%$ & $65.0 \%$ & 0.004 \\
\hline Gastroesophageal reflux disease & $22.4 \%$ & $7.5 \%$ & 0.033 \\
\hline Wheezing & $52.1 \%$ & $37.5 \%$ & 0.097 \\
\hline
\end{tabular}

Data are presented as mean $(95 \% \mathrm{Cl})$, unless otherwise stated. Characteristics with at least a suggestive association ( $p<0.10)$ are presented and based on chi-squared and Mann-Whitney U-tests.

accepted as the level of statistical significance but results showing a suggestive association $(\mathrm{p}<0.1)$ were also evaluated. All analyses were performed using SPSS version 22 for the personal computer (SPSS, Inc., Chicago, IL, USA).

\section{Results}

The response rate was $77.7 \%$ (205 subjects, mean age 52.1 years (9.0), 85.9\% females, table 2). The proportion of missing values was less than $1 \%$. In 2018, 165 subjects (80.5\%) reported that they were still experiencing cough.

Table 1 presents the factors that predicted cough in 2018 in the bivariate analyses.

The following factors were associated with cough in the multivariate analyses: gastro-oesophageal reflux disease (adjusted OR (aOR) 5.02 (95\% CI 1.10-22.83)), presence of a chemical trigger (aOR 2.88 (95\% CI (1.20-7.00)), duration of cough more than 1 year (aOR 2.80 (95\% CI 1.27-6.22)), frequent somatic symptoms (aOR 1.31 (95\% CI 1.07-1.59)), and low number of family members (aOR 0.71 (95\% CI 0.52-0.98)) (table 3).

From 2017 to 2018, the current daily smoking status had changed from $8.3 \%$ of subjects to $6.9 \%$ of subjects, current pet ownership from $39.7 \%$ to $41.9 \%$ of subjects and current moisture damage exposure status from $35.1 \%$ to $11.0 \%$ of subjects. Nonetheless, the inclusion of these factors into the multivariate analysis did not change the results.

\section{Discussion}

In the present sample consisting of a community-based subjects with chronic cough, as many as $80.5 \%$ still were suffering from cough when assessed 12 months later. In the multivariate analysis, the five factors

\section{TABLE 2 The characteristics at baseline of the 205 subjects who responded to the follow-up survey in 2018}

\begin{tabular}{|c|c|}
\hline Age years mean $\pm s D$ & $52.1 \pm 9.0$ \\
\hline Female sex & $176(85.9 \%)$ \\
\hline Body mass index $\mathrm{kg} \cdot \mathrm{m}^{-2}$ mean $\pm \mathrm{sD}$ & $28.1 \pm 5.6$ \\
\hline Current smokers & $17(8.3 \%)$ \\
\hline Ex-smokers & $51(24.9 \%)$ \\
\hline Pet ownership & $81(39.5 \%)$ \\
\hline Moisture damage in workplace or at home & $72(35.1 \%)$ \\
\hline Presence of gastro-oesophageal reflux disease with proton-pump inhibitors & $40(19.5 \%)$ \\
\hline Patients receiving medication & $25(62.5 \%)$ \\
\hline Presence of doctor diagnosed asthma with asthma medication & $62(30.2 \%)$ \\
\hline Patients receiving medication & $60(96.8 \%)$ \\
\hline Presence of chronic rhinitis treated with any kind of nasal sprays & $82(40.0 \%)$ \\
\hline Patients receiving medication & $50(61.0 \%)$ \\
\hline
\end{tabular}


TABLE 3 Multivariate adjusted odds ratios (aOR) between characteristics at baseline in 2017 and the presence of cough at the 12-month follow-up

\begin{tabular}{llc} 
Characteristic at baseline & aOR (95\% CI) & p-value \\
\hline Gastro-oesophageal reflux disease & $5.02(1.10-22.83)$ & 0.037 \\
Presence of a chemical trigger & $2.88(1.20-7.00)$ & 0.018 \\
Duration of cough more than 1 year & $2.80(1.27-6.22)$ & 0.011 \\
Somatic symptom sum" & $1.31(1.07-1.59)$ & 0.008 \\
Number of family members & $0.71(0.52-0.98)$ & 0.034 \\
\hline \#: per individual somatic symptom; ๆ: per number of family members other than the respondent.
\end{tabular}

at baseline that predicted cough at 12 months were 1) gastro-oesophageal reflux disease, 2) the presence of a chemical trigger, 3) duration of cough more than 1 year, 4) number of somatic symptoms, and 5) a low number of family members.

Gastro-oesophageal reflux disease was the most important predictor for persistent cough at 12 months after the initial evaluation among patients with chronic cough. The relationship between chronic cough and gastro-oesophageal reflux disease is rather complex and the exact pathophysiological mechanism underpinning this relationship remains unclear [19]. In patients with chronic cough, the passage of acid into the distal oesophagus increases the frequency of coughing [20] and elevates the cough reflex sensitivity to capsaicin [21]. Furthermore, it has been claimed that the major determinants of the cough seem to be the volume of the refluxate and the duration of the reflux episode rather than the acidity of the refluxate [22]. These findings could explain why acid-suppressive therapy has proven to be ineffective in reducing cough frequency in many placebo-controlled trials [23]. Given the fact that reflux seems to be a strong predictor for a poor prognosis in chronic cough, its proper treatment is of fundamental importance. According to the latest guidelines [19], the treatment of chronic cough due to gastro-oesophageal reflux should consist of diet modification to promote weight loss in overweight or obese patients, head-of-bed elevation and avoidance of meals $3 \mathrm{~h}$ before going to bed. Proton-pump inhibitors, $\mathrm{H}_{2}$-receptor antagonists or antacid therapy are recommended for patients who report heartburn and regurgitation. Those patients whose cough has been refractory to a 3-month trial of lifestyle and medical anti-reflux therapy and who are being evaluated for surgical management, should undergo a 24-h oesophageal manometry and $\mathrm{pH}$-metry monitoring and if peristalsis is adequate and oesophageal acid exposure is abnormal, anti-reflux surgery should be considered as a way of treating their chronic cough.

One may think that the under-medication of reflux in the population might explain the predictive value of reflux symptoms. Indeed, just 25 out of 40 subjects with symptomatic reflux used proton-pump inhibitors. However, it has been shown that the effect of any medical therapy is poor in reflux-associated cough. Therefore, it is unlikely that under-medication of reflux symptoms explains the association between reflux symptoms and the persistence of cough.

It should be noted that many patients with chronic cough possibly due to gastro-oesophageal reflux disease do not have the typical symptoms associated with gastro-oesophageal reflux disease (i.e. heartburn and regurgitation) [24]. In this study, we asked about the presence of gastro-oesophageal reflux disease based on validated symptoms [11]. This raises the following questions: what is the prevalence of gastro-oesophageal disease among chronic cough patients with atypical or absent reflux symptoms and should 24-h oesophageal manometry and $\mathrm{pH}$-metry be performed in all patients complaining of unexplained chronic cough?

The presence of a chemical trigger (either exhaust fumes, poor indoor air, cigarette smoke, strong odours or strong smells) was also a crucial predictor for persistence of cough. TERNESTEN-Hasséus et al. [30] have previously shown that chemical-sensitive patients coughed significantly more on inhaling capsaicin, and had significantly more other airway symptoms compared to those in the nonsensitive group. These findings fit to the concept of cough hypersensitivity syndrome [25], hence presence of a chemical trigger suggests a diagnosis of cough hypersensitivity syndrome. We think that the presence of a chemical trigger is an important part of the anamnesis of a patient suffering chronic cough.

In this study, a duration of cough lasting more than 1 year predicted the prolongation of chronic cough almost as strongly as the presence of a chemical trigger. The mechanism behind this finding might be central sensitisation, such as in chronic pain. As with chronic pain, continued stimulation may result in increased neuronal responsivity and sensitisation [26]. Given the fact that chronic cough is difficult to treat [4-6], careful diagnostic and therapeutic management should be done in the early phase of cough. 
The number of somatic symptoms predicted the presence of cough at 12 months. It seems likely that there are individual differences in the ways in which individuals recognise and report their symptoms, a phenomenon called somatisation. In the present study, somatisation was taken into account by calculating the somatic symptom sum. Previously it has been reported that there is a good association between somatisation symptoms and asthma symptoms [27]. A lower number of family members also predicted cough at 12 months. This is an interesting finding because the hygiene hypothesis has been proposed to lie behind atopy and atopic disease (i.e. family size is negatively associated with atopy and atopic disease) [28] but to the best to our knowledge, not previously with chronic cough. The protective effect of large families in atopy and allergic diseases is considered to be explained by the greater exposure to microbes in members of these families. The same mechanism does not necessarily explain our finding about the protective effect of larger family size.

Interesting negative findings are that neither asthma nor chronic rhinitis predicted cough at 12 months. These diseases had been quite well medically treated, similarly to gastro-oesophageal reflux disease (table 2). It can be postulated that asthma and chronic rhinitis are conditions that respond better to medical treatment in contrast to gastro-oesophageal disease, which requires lifestyle modifications rather than simply acid-suppressive therapy to effectively treat chronic cough. In addition, asthma and chronic rhinitis tend to be seasonal and this may have influenced the failure to detect a relationship with chronic cough.

Furthermore, the Leicester Cough Questionnaire did not predict cough prolongation, suggesting that severity of cough is not predictive for its prolongation. This is an important message to patients with chronic cough and also to doctors treating them. There is no reason for pessimism on the basis of cough severity at the initial evaluation.

There are several limitations to this study. The population consisted of working-age, public service employees, so the generalizability of the study may be somewhat limited. Individuals in the lower social classes and older persons are therefore underrepresented, and this may also partly explain the low smoking rate. Thus, the role of smoking in cough prolongation cannot be determined in this population. It should also be taken into account that all the data in this study are based on self-reported symptoms. Subjects also self-reported clinical diagnoses and medications and these were not rechecked from the electronic patient record system. Many patients with gastro-oesophageal reflux disease did not use proton-pump inhibitors, which may have affected the results. A single year is also a rather short time in the follow-up of chronic cough; in fact, we are well aware that the majority of cough patients may have suffered from cough for several years $[4,29]$. On the other hand, from the point of view of the patients, even suffering from this irritating disorder for 1 year is already a long time.

The strengths of the study include the community-based sample; the previous two studies that have examined the prognosis of chronic cough were conducted in a selected population (i.e. patients being treated in specialised cough clinics). In addition, this study includes more patients than the previous two studies combined $[5,6]$. The strength of this study is also its prospective, follow-up design. It is recognised that causal inference between risk factors and cough prolongation can be better investigated in a prospective, follow-up study than in one with a cross-sectional design. The baseline questionnaire was originally developed to investigate the risk factors of cough. Nonetheless, this questionnaire was comprehensive, the collection of risk factors was systematic, and the response rate was good (77.7\%).

In conclusion, this study is the first that has investigated the persistence of chronic cough and its risk factors in a community-based sample. It was found that the vast majority (i.e. 80\%) of patients still have cough at the 1-year follow-up, even though asthma and chronic rhinitis had been mainly adequately medically treated. Gastro-oesophageal reflux disease is the main indicator for cough persistence in chronic cough. Physicians should take a careful patient history about the presence of gastro-oesophageal reflux disease in a patient suffering from chronic cough. Treatment should be started, especially focusing on lifestyle modifications as well as anti-reflux therapy if needed. The presence of a chemical trigger, the duration of cough and the presence of other somatic symptoms should also be considered to get a proper assessment of the risk factors of prolongation of chronic cough.

Acknowledgments: We thank Seppo Hartikainen (Istekki Ltd, Kuopio, Finland) for his assistance in creating the electronic questionnaire and Ewen MacDonald (University of Eastern Finland, Kuopio, Finland) for the language check.

Conflict of interest: A.M. Lätti reports grants from The Kuopio Region Respiratory Foundation, The Research Foundation of the Pulmonary Diseases, the Foundation of the Finnish Anti-Tuberculosis Association, The Väinö and Laina Kivi Foundation and the state subsidy of the Kuopio University Hospital during the conduct of the study, and personal fees from Orion, Boehringer Ingelheim, Roche and AstraZeneca to visit international scientific meetings outside the submitted work. J. Pekkanen has nothing to disclose. H.O. Koskela reports grants from Kuopion Seudun Hengityssäätiö Foundation and Hengityssairauksien Tutkimussäätiö during the conduct of the study; personal fees from Mundipharma Ltd, Orion Pharma Ltd, Oy, Eli Lilly Finland Ltd and Boehringer Ingelheim Finland Ltd as payments for 
giving scientific lectures in gatherings organised by medical companies, personal fees from Takeda Leiras Ltd, Boehringer Ingelheim Ltd, Mundipharma Ltd and AstraZeneca Ltd to visit international scientific meetings, and owning shares of Orion Pharma Ltd worth €22 000 .

Support statement: This study was supported by Kuopion Yliopistollinen Sairaala, The Väinö and Laina Kivi Foundation, The Research Foundation of the Pulmonary Diseases, Kuopion Seudun Hengityssäätiö and Suomen Tuberkuloosin Vastustamisyhdistyksen Säätiö. Funding information for this article has been deposited with the Crossref Funder Registry.

\section{References}

1 Centers for Disease Control and Prevention. National Ambulatory Medical Care Survey: 2010 Summary Tables. Atlanta, Centers for Disease Control and Prevention, 2014

2 Wandell P, Carlsson AC, Wettermark B, et al. Most common diseases diagnosed in primary care in Stockholm, Sweden, in 2011. Fam Pract 2013; 30: 506-513.

3 French CL, Irwin RS, Curley FJ, et al. Impact of chronic cough on quality of life. Arch Intern Med 1998; 158: $1657-1661$.

4 Chamberlain SA, Garrod R, Douiri A, et al. The impact of chronic cough: a cross-sectional European survey. Lung 2015; 193: 401-408.

5 Koskela HO, Latti AM, Purokivi MK. Long-term prognosis of chronic cough: a prospective, observational cohort study. BMC Pulm Med 2017; 17: 146.

6 Yousaf N, Montinero W, Birring SS, et al. The long-term outcome of patients with unexplained chronic cough Respir Med 2013; 107: 408-412.

7 National Institute for Health and Welfare. Health Behaviour and Health among the Finnish Adult Population National Institute for Health and Welfare. https://thl.fi/en/tutkimus-ja-kehittaminen/tutkimukset-ja-hankkeet/ aikuisten-terveys-hyvinvointi-ja-palvelututkimus-ath/aiemmat-tutkimukset/suomalaisen-aikuisvaeston-terveyskaytta ytyminen-ja-terveys-avtk. Date last updated: August 16, 2019. Date last accessed: May 7, 2020.

8 National Institute for Health and Welfare. The National FINRISK Study. https://thl.fi/en/web/thlfi-en/researchand-expertwork/population-studies/the-national-finrisk-study. Date last updated: October 2, 2017. Date last accessed: May 7, 2020

9 Sa-Sousa A, Jacinto T, Azevedo LF, et al. Operational definitions of asthma in recent epidemiological studies are inconsistent. Clin Transl Allergy 2014; 4: 24.

10 Fokkens WJ, Lund VJ, Mullol J, et al. European Position Paper on Rhinosinusitis and Nasal Polyps 2012. Rhinol Suppl 2012; 50: 1-298.

11 El-Serag HB, Sweet S, Winchester CC, et al. Update on the epidemiology of gastro-oesophageal reflux disease: a systematic review. Gut 2014; 63: 871-880.

12 Kroenke K, Spitzer RL, Williams JB. The Patient Health Questionnaire-2: validity of a two-item depression screener. Med Care 2003; 41: 1284-1292.

13 Birring SS, Prudon B, Carr AJ, et al. Development of a symptom specific health status measure for patients with chronic cough: Leicester Cough Questionnaire (LCQ). Thorax 2003; 58: 339-343.

14 Morice AH, Millqvist E, Bieksiene K, et al. ERS guidelines on the diagnosis and treatment of chronic cough in adults and children. Eur Respir J 2020; 55: 1901136.

15 Sousa SIV, Ferraz C, Alvim-Ferraz MCM, et al. Spirometric tests to assess the prevalence of childhood asthma at Portuguese rural areas: influence of exposure to high ozone levels. Environ Int 2011; 37: 474-478.

16 Colak Y, Nordestgaard BG, Laursen LC, et al. Risk factors for chronic cough among 14,669 individuals from the general population. Chest 2017; 152: 563-573.

17 Lätti AM, Pekkanen J, Koskela HO. Defining the risk factors for acute, subacute and chronic cough: a cross-sectional study in a Finnish adult employee population. BMJ Open 2018; 8: e022950.

18 Lätti AM, Pekkanen J, Koskela HO. Predictors of prolongation in recent-onset cough. ERJ Open Res 2019; 5 00238-2018

19 Kahrilas PJ, Altman KW, Chang AB, et al. Chronic cough due to gastroesophageal reflux in adults: CHEST guideline and expert panel report. Chest 2016; 150: 1341-1360

20 Ing AJ, Ngu MC, Breslin AB. Pathogenesis of chronic persistent cough associated with gastroesophageal reflux. Am J Respir Crit Care Med 1994; 149: 160-167.

21 Javorkova N, Varechova S, Pecova R, et al. Acidification of the oesophagus acutely increases the cough sensitivity in patients with gastro-oesophageal reflux and chronic cough. Neurogastroenterol Motil 2008; 20: 119-124.

22 Herregods TV, Pauwels A, Jafari J, et al. Determinants of reflux-induced chronic cough. Gut 2017; 66: 2057-2062.

23 Chang AB, Lasserson TJ, Gaffney J, et al. Gastro-oesophageal reflux treatment for prolonged non-specific cough in children and adults. Cochrane Database Syst Rev 2011: CD004823.

24 Poe RH, Kallay MC. Chronic cough and gastroesophageal reflux disease: experience with specific therapy for diagnosis and treatment. Chest 2003; 123: 679-684.

25 Morice AH, Faruqi S, Wright CE, et al. Cough hypersensitivity syndrome: a distinct clinical entity. Lung 2011; 189: 73-79.

26 Bourke JH, Langford RM, White PD. The common link between functional somatic syndromes may be central sensitisation. J Psychosom Res 2015; 78: 228-236.

27 Rona RJ, Smeeton NC, Amigo H, et al. Do psychological distress and somatization contribute to misattribution of asthma? A Chilean study. J Psychosom Res 2007; 62: 23-30.

28 Jarvis D, Chinn S, Luczynska C, et al. The association of family size with atopy and atopic disease. Clin Exp Allergy 1997; 27: 240-245.

29 Koskela HO, Lätti AM, Pekkanen J. The impacts of cough: a cross-sectional study in a Finnish adult employee population. ERJ Open Res 2018; 4: 00113-2018.

30 Ternesten-Hasséus E, Larsson C, Larsson S. Capsaicin sensitivity in patients with chronic cough - results from a cross-sectional study. Cough 2013; 9: 5. 